\title{
Repeatability of measures of inflammatory cell number in bronchial biopsies in atopic asthma
}

\author{
J.K. Sont*, L.N.A. Willems*, C.E. Evertse*, R. Hooijer**, P.J. Sterk*, \\ J.H.J.M. van Krieken**
}

Repeatability of measures of inflammatory cell number in bronchial biopsies in atopic asthma. J.K. Sont, L.N.A. Willems, C.E. Evertse, R. Hooijer, P.J. Sterk, J.H.J.M. van Krieken. (CERS Journals Ltd 1997.

ABSTRACT: Airway pathology is increasingly considered to be a major outcome in asthma research. The aim of this study was to examine the intra-observer, within-section and between-biopsy repeatability, together with the implications for statistical power of a computerized quantitative analysis of inflammatory cell numbers in the lamina propria in bronchial biopsy specimens from atopic asthmatic subjects.

Thirty six atopic adults (aged 19-40 yrs) with mild to moderate asthma (baseline forced expiratory volume in one second (FEV1) $\geq 50 \%$ of predicted value, methacholine $\left(\mathrm{PC}_{20}\right)$ range $\left.0.02-18.2 \mathrm{mg} \cdot \mathrm{mL}^{-1}\right)$ at various levels of treatment $(25$ subjects on inhaled steroids) entered the study. Biopsies were taken from the (sub)segmental carinae of the right lower and middle lobe and from the main carina. Specimens were snap-frozen and immunohistochemical staining was performed on cryostat sections with monoclonal antibodies against: (secreted) eosinophil cationic protein (EG1, EG2), mast cell tryptase (AA1), CD45, CD22, CD4, CD8, CD25, and CD45RO. Using a computerized system, the number of positively stained cells in the lamina propria was counted.

When considering all cell types together, satisfactory intraclass correlation coefficients (ICC) values were obtained for intra-observer, within-section and betweenbiopsy repeatability, being $0.90,0.80$ and 0.81 , respectively. The analysis of repeatability for individual cell types revealed ICC values ranging $\mathbf{0 . 4 7 - 0 . 8 2}$ for intra-observer, $0.44-0.76$ for within-section and $0.37-0.67$ for between-biopsy repeatability. The results imply that a sample-size between eight and 25 subjects is needed to detect at least one doubling difference in cell number per $0.1 \mathrm{~mm}^{2}$ for a particular inflammatory cell type in a study, using a within-group design with $\alpha=0.05$ and power of 0.80 . A sample-size of 13-48 subjects per group is required to detect the same difference between the groups in a parallel design.

Eur Respir J 1997; 10: 2602-2608.

\author{
*Dept of Pulmonology, and **Dept of \\ Pathology, Leiden University Medical
} Centre, The Netherlands.

Correspondence: J.K. Sont

Lung Function Laboratory, C2-P

Dept of Pulmonology

Leiden University Medical Centre

P.O. Box 9600

NL-2300 RC Leiden

The Netherlands

Keywords: Asthma

bronchial biopsy

immunohistochemistry

pathology

Received: June 201997

Accepted after revision July 81997

This study was supported by grant 92.45 of The Netherlands Asthma Foundation
Asthma is considered a chronic inflammatory disorder of the airways, characterized by a specific infiltrate of mast cells, eosinophils and lymphocytes in the airway epithelium, and lamina propria [1]. The relationship of inflammatory cells in the airways to specific clinical patterns, prognosis or response to treatment has not yet been clarified [2-4].

During the last few years, fibreoptic bronchoscopy has become widely available as a research tool for studies on the pathology of asthma. The inflammatory cell infiltrate in bronchial biopsy specimens of patients with asthma is generally assessed within the lamina propria and/or the bronchial epithelium by a computerized method and expressed as cell number per unit area [5]. However, infiltration of inflammatory cells can be a focal phenomenon, which is difficult to quantify [6], occasionally requiring semi-quantitative scoring methods $[6,7]$.

There is only sparse information on the variability of inflammatory cell numbers between biopsies of different sites and within-sections [8]. Such data would have implications for the statistical power of intervention studies with outcome measures obtained from biopsy specimens. In particular, studies with a parallel group design might require relatively large sample-sizes as compared to studies with a within-group design [9].

Therefore, the aim of this study was to examine the intra-observer, within-section and between-biopsy repeatability of measurement of the cellular infiltrate in biopsy specimens taken at (sub)segmental and central sites during one single bronchoscopy from atopic asthmatic subjects who enrolled in a long-term parallel trial. To that end, we determined the number of inflammatory cells per unit area in the lamina propria in biopsy specimens by a quantitative video assisted computerized method. Finally, the statistical power in parallel and within-group study designs were calculated.

\section{Methods}

\section{Subjects}

Thirty six atopic adults visiting the outpatient clinic of the Leiden University Hospital for their asthma who enrolled in a long-term parallel trial (Asthma Management Project University of Leiden (AMPUL)) participated in this study. They were all nonsmokers and covered a wide range in asthma severity (table 1). All patients 
Table 1. - Patient characteristics

\begin{tabular}{|c|c|c|c|c|c|c|c|c|}
\hline $\begin{array}{l}\text { Patient } \\
\text { No. }\end{array}$ & $\begin{array}{l}\text { Age } \\
\text { yrs }\end{array}$ & Sex & $\begin{array}{l}\text { Steroid } \\
\text { usage }\end{array}$ & $\begin{array}{c}\beta_{2} \text {-agonists } \\
\text { puffs } \cdot \text { week }^{-1}\end{array}$ & $\begin{array}{l}\text { FEV1 } \\
\% \text { pred }\end{array}$ & $\begin{array}{c}\text { Reversibility } \\
\% \text { pred }\end{array}$ & $\begin{array}{c}\text { PEF variability } \\
\%\end{array}$ & $\begin{array}{l}\mathrm{PC} 20 \text {, meth } \\
\mathrm{mg} \cdot \mathrm{mL}^{-1}\end{array}$ \\
\hline 1 & 21 & M & Yes & 14 & 51 & 38 & 18.0 & 0.45 \\
\hline 2 & 23 & M & Yes & 17 & 64 & 22 & 27.0 & 0.76 \\
\hline 3 & 26 & $\mathrm{~F}$ & Yes & 5 & 66 & 17 & 15.7 & 0.27 \\
\hline 4 & 40 & M & Yes & 18 & 68 & 19 & 12.8 & 5.70 \\
\hline 5 & 25 & M & No & 0 & 68 & 22 & 21.5 & 0.02 \\
\hline 6 & 33 & M & Yes & 13 & 82 & 23 & 26.6 & 0.68 \\
\hline 7 & 43 & $\mathrm{~F}$ & No & 3 & 82 & 8 & 4.5 & 1.72 \\
\hline 8 & 40 & $\mathrm{M}$ & Yes & 0 & 82 & 4 & 13.3 & 0.82 \\
\hline 9 & 20 & M & Yes & 2 & 82 & 15 & 5.7 & 0.11 \\
\hline 10 & 23 & M & No & 0 & 84 & 37 & 11.9 & 0.07 \\
\hline 11 & 21 & M & Yes & 0 & 86 & 1 & 6.3 & 0.43 \\
\hline 12 & 22 & M & Yes & 4 & 87 & 3 & 5.1 & 18.17 \\
\hline 13 & 19 & M & No & 5 & 87 & 11 & 2.4 & 0.68 \\
\hline 14 & 21 & M & Yes & 0 & 88 & 16 & 3.4 & 3.42 \\
\hline 15 & 26 & M & No & 0 & 90 & 8 & 6.3 & 0.36 \\
\hline 16 & 20 & M & No & 20 & 90 & 11 & 2.4 & 1.01 \\
\hline 17 & 26 & M & Yes & 0 & 91 & 19 & 2.1 & 2.01 \\
\hline 18 & 21 & M & No & 3 & 92 & 0 & 9.3 & 0.70 \\
\hline 19 & 19 & M & Yes & 0 & 92 & 8 & 6.3 & 0.26 \\
\hline 20 & 29 & M & Yes & 14 & 93 & 8 & 4.9 & 0.63 \\
\hline 21 & 19 & $\mathrm{~F}$ & No & 0 & 93 & 7 & 5.4 & 1.03 \\
\hline 22 & 26 & $\mathrm{M}$ & Yes & 50 & 96 & 10 & 9.2 & 0.28 \\
\hline 23 & 35 & $\mathrm{~F}$ & Yes & 2 & 96 & 17 & 9.7 & 0.38 \\
\hline 24 & 24 & M & No & 2 & 96 & 18 & 6.0 & 0.21 \\
\hline 25 & 25 & $\mathrm{~F}$ & Yes & 2 & 97 & 5 & 2.6 & 3.86 \\
\hline 26 & 19 & $\mathrm{~F}$ & No & 1 & 97 & 17 & 1.7 & 0.38 \\
\hline 27 & 22 & $\mathrm{M}$ & Yes & 14 & 98 & 8 & 7.0 & 0.46 \\
\hline 28 & 32 & $\mathrm{~F}$ & Yes & 1 & 99 & 16 & 7.1 & 0.22 \\
\hline 29 & 41 & $\mathrm{~F}$ & Yes & 0 & 99 & 4 & 6.0 & 1.63 \\
\hline 30 & 34 & $\mathrm{~F}$ & Yes & 28 & 101 & 5 & 10.7 & 0.32 \\
\hline 31 & 16 & $\mathrm{~F}$ & No & 1 & 102 & 15 & 3.3 & 0.04 \\
\hline 32 & 45 & $\mathrm{~F}$ & Yes & 3 & 107 & 8 & 15.8 & 0.49 \\
\hline 33 & 32 & $\mathrm{~F}$ & Yes & 5 & 110 & 0 & 5.0 & 7.61 \\
\hline 34 & 26 & $\mathrm{~F}$ & Yes & 1 & 111 & 5 & 9.1 & 0.27 \\
\hline 35 & 36 & $\mathrm{M}$ & Yes & 6 & 113 & 6 & 8.8 & 3.16 \\
\hline 36 & 26 & M & Yes & 14 & 120 & 1 & 8.4 & 0.68 \\
\hline Mean & 27.2 & & & 6.9 & 90.6 & 12.0 & 8.9 & 0.61 \\
\hline SD & 7.8 & & & 10.3 & 14.5 & 9.2 & 6.4 & 1.99 \\
\hline
\end{tabular}

Peak expiratory flow (PEF) variability is expressed as (highest value - lowest)/highest. Provocative concentration of methacholine causing a $20 \%$ fall in FEV1 (PC20,meth) is expressed as the geometric mean and SD, in doubling doses. FEV1: forced expiratory volume in one second; \% pred: percentage of predicted value; M: male; F: female.

had a history of episodic chest tightness and wheezing on the chest in the previous year and were at various levels of treatment (25 subjects on inhaled steroids). Symptom severity, bronchodilator usage and peak flow rates were recorded on diary cards [10]. Atopy, prebronchodilator forced expiratory volume in one second (FEV1) ( $>50 \%$ of predicted [11] and $>1.5 \mathrm{~L}$ ), post-bronchodilator FEV1 (400 $\mu \mathrm{g}$ salbutamol; $>80 \%$ pred) and the provocative concentration of methacholine causing a $20 \%$ fall in FEV1 (PC20,meth geometric mean 0.61 $\left.\mathrm{mg} \cdot \mathrm{mL}^{-1}\right)$ were assessed according to recently published methods [12]. Symptoms were additionally controlled by on demand usage of short-acting beta-agonists that were withheld for at least $8 \mathrm{~h}$ before the challenge test. All subjects gave their informed consent, and the study was approved by the local Ethics Committee.

\section{Bronchoscopy}

Fibreoptic bronchoscopy was carried out by an experienced investigator (LNAW), using a standardized pro- tocol, according to recent recommendations [13, 14]. Each procedure involved detailed explanation, premedication, local anaesthesia, bronchoscopy, and sampling according to a recently published protocol [10]. Three bronchial biopsies were taken at (sub)segmental level from right lower lobe subsegments, the middle lobe and the main carina using a pair of cup forceps (FB-21C; Olympus, Tokyo, Japan).

\section{Processing of endobronchial biopsies}

Biopsy samples were immediately embedded in optimal cutting temperature (OCT) medium (Miles Inc. Diagnostics Division, Elkhart, USA), and snap-frozen in isopentane cooled by dry ice. Samples were stored at $-70^{\circ} \mathrm{C}$ pending further processing. Six micrometre cryostat sections were air dried for $1 \mathrm{~h}$, and fixed in a mixture of equal parts acetone:methanol for $2 \mathrm{~min}$. Besides haematoxylin-eosin, immunohistochemical staining was performed using an indirect immunoperoxidase technique with the following monoclonal antibodies against: eosinophils staining for eosinophil cationic protein 
(EG1) or the secreted form of eosinophil cationic protein (EG2) (both Pharmacia, Sweden); mast cell tryptase (AA1, donated by R. Djukanović, Southampton University General Hospital, Southampton, UK); total leucocytes (CD45); B-cells (CD22); T-lymphocytes (CD3); T-helper cells (CD4); T-suppressor cells (CD8); activated T-cells (CD25) (all Becton Dickinson, Mountain View, CA, USA); and T-cells CD45RO (UCHL1) (DAKO, Glostrup, Denmark). In short, the sections were incubated with monoclonal antibodies at a dilution of $1: 40$ in $1 \%$ bovine serum albumin (BSA)/phosphate buffered saline (PBS) at $4^{\circ} \mathrm{C}$ for $1 \mathrm{~h}$. After washing with PBS $(3 \times 5$ $\min )$, the slides were incubated with rabbit- $\alpha$-mouseperoxidase (rabbit antimouse (RAM)-horseradish peroxidase (HRP) 1:50 in 1\% BSA/PBS + 20\% normal human serum; DAKO) for $30 \mathrm{~min}$. The slides were again washed and incubated with swine- $\alpha$-rabbit-peroxidase (swine antirabbit (SWAR)-HRP 1:50 in 1\% BSA/PBS + $10 \%$ normal human serum (NHS); DAKO) for another $30 \mathrm{~min}$. After washing, the slides were rinsed in acetate buffer $0.1 \mathrm{M}(\mathrm{pH} 5.0)$. The reaction was revealed (7 min) using 5\% 3-amino-9-erthylcarbazole (AEC) in acetate buffer. The reaction was stopped with aqua-dest and counterstained with Mayer-hematoxyline for $30 \mathrm{~s}$. The slides were then put under tapwater for 5 min, left to dry and mounted with Kaisers glycerine.

\section{Quantification}

All biopsy specimens were coded and sections were examined by one investigator (JKS) in a blinded fashion, by means of a video interactive display analysis system (VIDAS II, Kontron Electronik GmbH, Munich, Germany). Using the $200 \times$ magnification, the first available area fulfilling criteria on well preserved tissue structure and/or bronchus associated lymphoid tissue (BALT; confirmed by B-cell (CD22) staining) was chosen to serve as the basis for further computer-aided analysis. Within the area filling the video screen $\left(0.123 \mathrm{~mm}^{2}\right)$ we delineated the widest possible $125 \mu \mathrm{m}$ deep zone beneath the epithelial reticular basement membrane excluding damaged tissue, mucus-secreting glands and airway smooth muscle. This resulted in an average analysed area of $35,000 \mu \mathrm{m}^{2}$ per video screen (at least $10,000 \mu \mathrm{m}^{2}$ ); two such areas were analysed per biopsy section. Within the delineated area the number of positively stained nucleated inflammatory cells was counted and expressed as the number of cells $\cdot 0.1 \mathrm{~mm}^{-2}$.

\section{Statistical analysis}

Repeatability of cell counts was analysed for each individual cell type separately, and for all cell types together. Intra-observer repeatability was assessed by counting the number of inflammatory cells per unit area 1 week apart using the biopsy specimens from the first 19 subjects. The biopsy specimens of the other 17 subjects were used to assess within-section variability by counting the inflammatory cells on a single occasion in two different areas within the same biopsy section. The average values of cells per area at the two occasions in all subjects were used to assess variability between the biopsies obtained from different sites in the same patient (between-biopsy variability).
Although nonparametric analysis is frequently used in biopsy studies [5,6], we applied parametric analysis because sample-size estimation within the nonparametric framework is still under development and the parametric technique has the advantage of providing a detectable difference in the unit of measurement. Therefore, we examined in detail whether the distribution of the (differences in) cell counts fulfilled the assumptions underlying parametric analysis. Whether the differences between counts were proportional to their mean was checked by linear regression with the absolute value of the differences in cell number between two occasions as the dependent variable and their average value as the independent variable. Because this appeared to be the case for all cell types, the number of cells $\cdot 0.1 \mathrm{~mm}^{-2}$ was $\log$ transformed, after addition of 1 to allow for transformation of zero values [15]. The differences in mean cell numbers between the three biopsy sites were tested by repeated measures analysis of variance (ANOVA). The intra-observer, within-section and between-biopsy repeatability was assessed by both the coefficient of variation [15] and by the intra-class correlation coefficient (ICC) [16] for the overall assessments of cell counts as well separately as for the individual cell types.

Sample-size estimations were performed to detect at least one halving or doubling in cell number for a within-group and a parallel study design with $\alpha=0.05$ (twosided) and $\beta=0.20$ (power $=1 \beta=0.80$, one-sided), and were based on the SD of the differences between the biopsy specimens as assessed from a repeated measures ANOVA [17]. Power-curves were constructed for a study with a parallel group design to detect at least one halving or doubling in cell number between the studygroups for sample sizes ranging $\mathrm{n}=10-30$ per group $(\alpha=0.05$, two-sided $)$.

\section{Results}

A total of $86(80 \%)$ evaluable biopsy specimens for light microscopic examination were obtained from the 36 subjects. The geometric mean number (SD) of (sub)populations of leucocytes per unit area (cells. $0.1 \mathrm{~mm}^{-2}$, SD in doubling cell numbers) in the lamina propria of biopsies at the subsegmental level of the right lower lobe, segmental level of the middle lobe and central level of the main carina are shown in table 2. CD25 and CD22

Table 2. - Numbers of cells per unit area in lamina propria at (sub)segmental and central level in 36 atopic asthmatic subjects

\begin{tabular}{|c|c|c|c|c|c|c|}
\hline \multirow[b]{2}{*}{ Cell type } & \multicolumn{2}{|c|}{$\begin{array}{l}\text { Right lower lobe } \\
\qquad(\mathrm{n}=35)\end{array}$} & \multicolumn{2}{|c|}{$\begin{array}{l}\text { Middle lobe } \\
\quad(\mathrm{n}=29)\end{array}$} & \multicolumn{2}{|c|}{$\begin{array}{l}\text { Main carina } \\
\quad(\mathrm{n}=28)\end{array}$} \\
\hline & Mean & SD & Mean & $\overline{\mathrm{SD}}$ & Mean & SD \\
\hline CD45+ & 155 & 0.9 & 146 & 1.0 & 150 & 1.0 \\
\hline EG1+ & 8.8 & 1.7 & 7.5 & 1.9 & 7.0 & 1.6 \\
\hline EG2+ & 7.6 & 1.9 & 6.0 & 2.0 & 6.2 & 1.8 \\
\hline AA1+ & 15 & 1.1 & 15 & 1.1 & 19 & 1.1 \\
\hline CD3+ & 121 & 1.1 & 126 & 0.9 & 136 & 1.1 \\
\hline CD4+ & 68 & 1.1 & 82 & 1.1 & 65 & 1.3 \\
\hline CD8+ & 65 & 1.0 & 71 & 0.9 & 63 & 1.1 \\
\hline CD45RO+ & 172 & 0.9 & 159 & 1.0 & 159 & 1.0 \\
\hline
\end{tabular}

Values are geometric means and standard deviations (doubling cell numbers), in units of cells $\cdot 0.1 \mathrm{~mm}^{-2}$. 
Table 3. - Repeatability of inflammatory cell number per $0.1 \mathrm{~mm}^{2}$ of lamina propria and sample-size estimation

\begin{tabular}{|c|c|c|c|c|c|c|c|c|c|}
\hline \multirow[b]{2}{*}{ Cell type } & \multicolumn{2}{|c|}{$\begin{array}{c}\text { Intra- } \\
\text { observer }\end{array}$} & \multicolumn{2}{|c|}{ Within-section } & \multicolumn{2}{|c|}{ Between-biopsy } & \multicolumn{3}{|c|}{ Sample-size } \\
\hline & $\begin{array}{c}\mathrm{CV} \\
\%\end{array}$ & ICC & $\begin{array}{c}\mathrm{CV} \\
\%\end{array}$ & $\mathrm{ICC}$ & $\begin{array}{c}\mathrm{CV} \\
\%\end{array}$ & $\mathrm{ICC}$ & SDD & nwithin & nbetween \\
\hline All & 27 & 0.90 & 27 & 0.80 & 31 & 0.81 & 1.23 & 14 & 26 \\
\hline CD45+ & 25 & 0.57 & 18 & 0.76 & 23 & 0.56 & 0.94 & 9 & 16 \\
\hline EG1+ & 25 & 0.81 & 42 & 0.52 & 40 & 0.56 & 1.51 & 20 & 38 \\
\hline EG2+ & 27 & 0.82 & 34 & 0.65 & 53 & 0.56 & 1.72 & 25 & 48 \\
\hline AA $1+$ & 22 & 0.56 & 31 & 0.44 & 24 & 0.67 & 0.82 & 8 & 13 \\
\hline $\mathrm{CD} 3+$ & 20 & 0.73 & 23 & 0.68 & 28 & 0.50 & 1.04 & 11 & 19 \\
\hline CD4+ & 34 & 0.69 & 35 & 0.53 & 32 & 0.40 & 1.18 & 13 & 24 \\
\hline CD8+ & 30 & 0.52 & 21 & 0.74 & 28 & 0.37 & 1.04 & 11 & 19 \\
\hline CD45RO+ & 30 & 0.47 & 15 & 0.75 & 27 & 0.55 & 0.98 & 10 & 17 \\
\hline
\end{tabular}

CV: coefficient of variation; ICC: intraclass correlation coefficient [16]; SDD: standard deviation of differences between two biopsies in doubling cell numbers; nwithin: total number of subjects needed to detect at least one doubling difference in cell number in a within-group design with $\alpha=0.05$ and $\beta=0.20$; nbetween: total number of subjects needed to detect at least one doubling dif-

a)

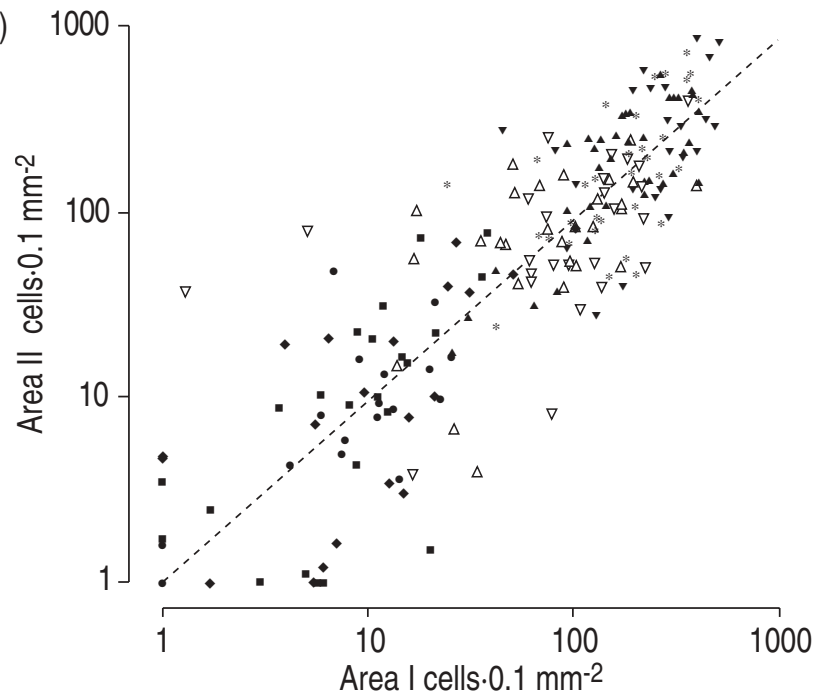

c) 1000 b)

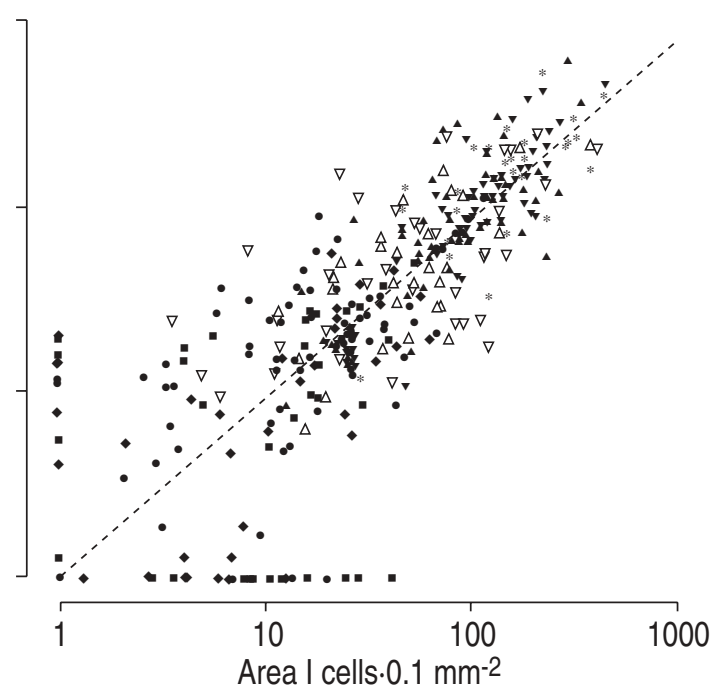

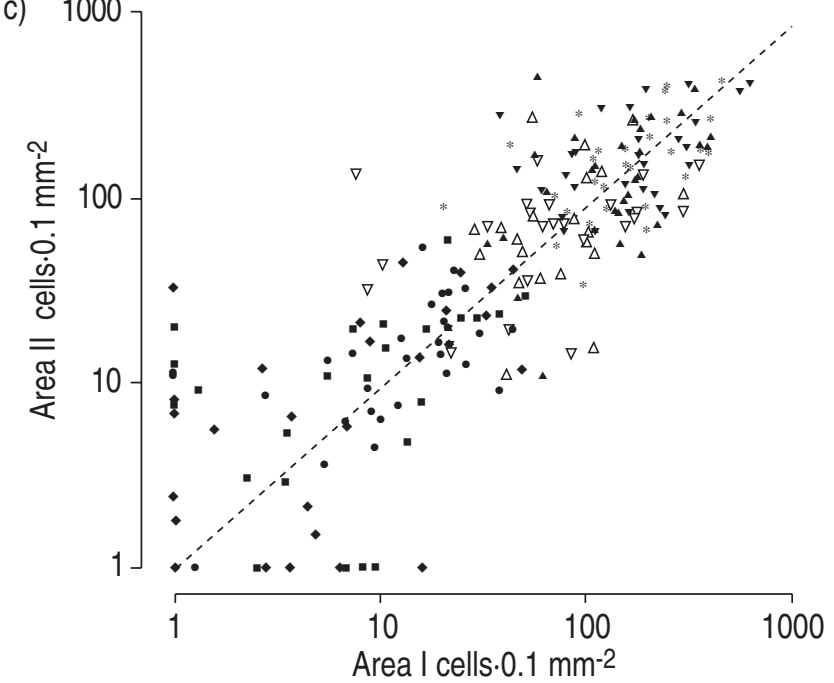

Fig. 1. - Identity plots of all counts of inflammatory infiltrate in the lamina propria of bronchial biopsy specimens in 36 asthmatic subjects: a) intra-observer (intraclass correlation coefficient $($ ICC $)=0.90)$; within-section $($ ICC $=0.80)$; and c) between-biopsy repeatability $($ ICC $=0.81$ ). The

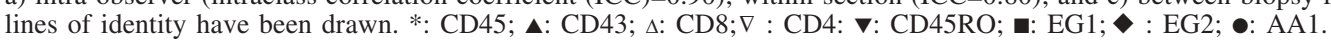




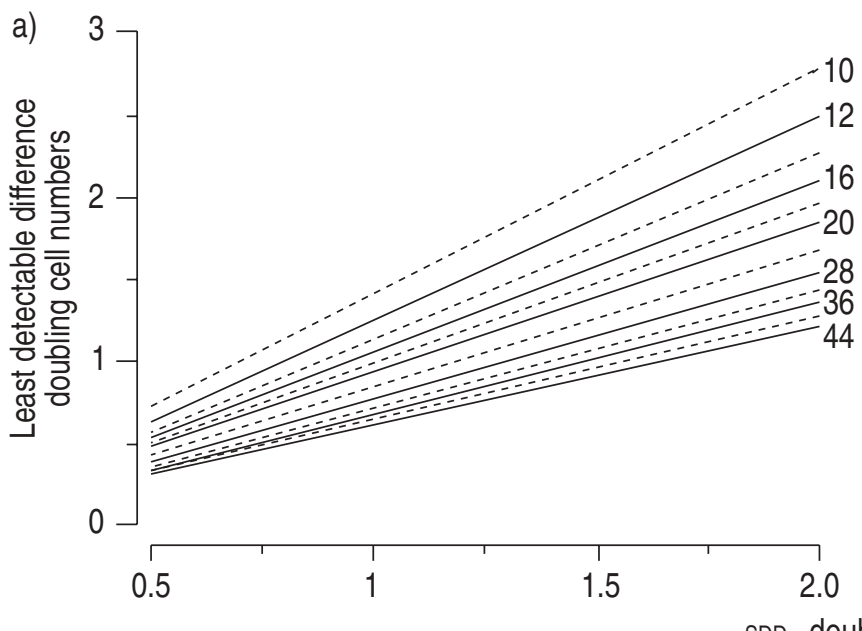

b)

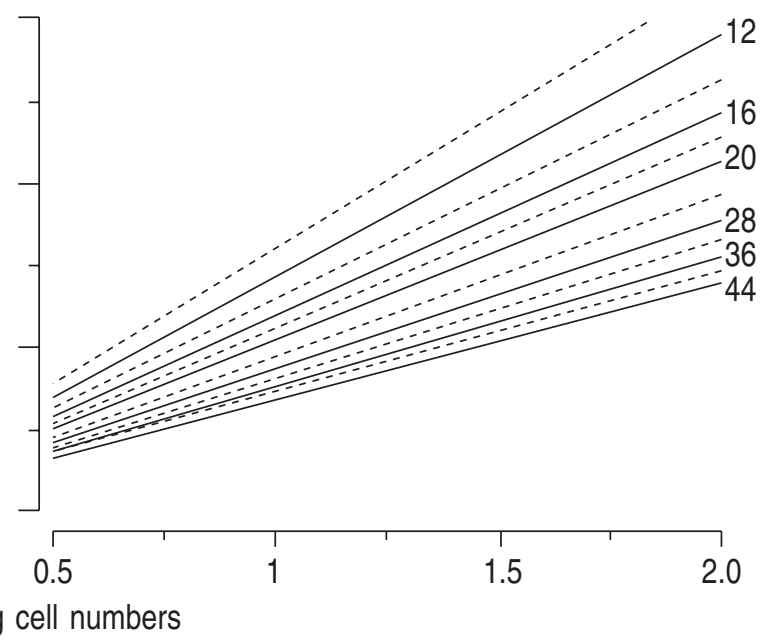

Fig. 2. - Power-curves for the detectable difference of inflammatory cell number for: a) power=0.80, $\beta=0.20$ one-sided; and b) power=0.90, $\beta=0.10$ one-sided. Curves are presented as doublings on the ordinate, based on the assumption of normality after log-transformation, with their given standard deviations of differences (SDD) on the abscissa and as shown in table 3. A parallel group design was used ( $\alpha=0.05$, two-sided). Values printed adjacent to each curve represent the number of patients per group.

positive cells were rarely found and were, therefore, not included in the statistical analysis. Except for an increased number of mast cells at the main carina as compared to the more peripheral sites $(\mathrm{p}=0.01)$, there were no significant differences in cell numbers between the three localizations for all cell types (Multivariate ANOVA; $\mathrm{p}>0.28$ ).

The repeatability data and sample-size estimations are summarized in table 3. Identity plots for intra-observer, within-section and between-biopsy repeatability are depicted in figure 1 . When considering all cell types together, satisfactory ICC values were obtained for intra-observer, within-section and between-biopsy repeatability, the values being 0.90, 0.80 and 0.81 , respectively. The analysis of repeatability for individual cell types revealed relatively lower ICC values, ranging $0.47-0.82$ for intraobserver, $0.44-0.76$ for within-section and $0.37-0.67$ for between-biopsy repeatability (table 3 ).

Estimations of sample-sizes that are needed to detect at least one doubling difference in cell number per 0.1 $\mathrm{mm}^{2}$ for a particular inflammatory cell type are given in table 3 for a within-group and parallel study design with $\alpha=0.05$ and power of 0.80 . The number of subjects for a within-group design ranges 8-25 subjects for AA1 and EG2 positive cells, respectively. For a parallel study design these sample-sizes vary between 13 and 48 subjects per group for AA1 and EG2 positive cells, respectively.

Figure 2 shows the power curves that were constructed to detect at least a halving or doubling in number of inflammatory cells per $0.1 \mathrm{~mm}^{2}$ with given standard deviations of differences between repeated measurements, in a parallel group design for sample-sizes ranging 10-30 subjects per study arm. These power curves are generally applicable for any given standard deviation of differences expressed in doubling differences (SD of $\log$ transformed data divided by $\log (2)$ ).

\section{Discussion}

In the present study, we observed that quantitative assessment of inflammatory cells per unit area of lam- ina propria by a computerized method is reproducible with respect to both intra-observer, within-section and betweenbiopsy repeatability. Based on the observed betweenbiopsy repeatability, intervention studies with feasible sample-sizes will have sufficient power to detect at least a halving or doubling difference in cell number in within-group (8-25 subjects) as well as parallel group designs (13-48 subjects per group).

This study aimed to evaluate the methodology of assessment of airway pathology in bronchial biopsies of patients with asthma and to examine the implications for the sample-size of within-group and parallel trials. When considering changes in inflammatory cells with time, one should ideally obtain cell counts in biopsies from two repeated bronchoscopies performed without intervention. However, we estimated the repeatability of the cell counts from two repeated bronchoscopies by analysing distinct areas of bronchial biopsies taken during the same bronchoscopy, thereby reducing the duration of the intervention period to zero. We believe this is justifiable, because in studies with a parallel design it is appropriate and common to test the difference in the distribution of inflammatory cell counts between the two arms at the end of the study. In order to do this, it is sufficient to know the repeatability at a single timepoint. Valid sample-size estimations for repeated biopsies can be obtained from the present analysis when time-dependent variability is smaller or as large as within-subject variability. Otherwise, our sample-size estimates can serve as lower bound proxies for all other time-intervals. Furthermore, one has to consider that sample-size estimations always need fine-tuning for each individual study. Besides the time-interval, there may be relevant differences with respect to the patient selection and methods of measurement, which may influence the repeatability.

In the present study intra-observer repeatability was determined by reassessing the same biopsy sections with an interval of at least 1 week. Within-section repeatability was assessed from two random areas within a single biopsy assessed by the same observer on the same occasion. Other investigators have previously reported 
on two or three repeat measurements of inflammatory cell numbers per area from single biopsy sections in asthma. Performing a similar analysis of intra-observer repeatability as in the present study, FRAENKEL et al. [18] reported an ICC of 0.90 for inflammatory cell counts in the submucosa of entire sections, omitting glandular areas. BRADLEY et al. [19] and BENTLEY et al. [20] reported coefficients of variation that ranged $4-11 \%$ for repeat cell counts of CD45, CD3, CD4, CD8, and EG2 positive cells within a $115 \mu \mathrm{m}$ deep zone beneath the reticular basement membrane. The intra-observer coefficients of variation that we observed were higher, ranging 22 $34 \%$ for EG1+ and CD4+ cells, respectively. Apparently, the assessment of intra-observer repeatability, which includes assessment of distinct areas within a single section, demonstrates less repeatable inflammatory cell counts. However, repeatability based on assessment of distinct areas seems to be more realistic in sample-size calculations for within-group or parallel study designs. This interpretation is supported by the observation that the values that we obtained for within-section and between-biopsy coefficients of variation were within a similar range as those for the intra-observer repeatability. Furthermore, AzZAwi et al. [21] reported a coefficient of variation of $22.6 \%$ for between-biopsy assessments of CD45+ cells, which is in keeping with our finding of $23 \%$.

Recently, three randomized double-blind placebo controlled parallel group trials were published in which the effect of 6 weeks treatment with low-dose oral theophylline [22], 4 months treatment with inhaled corticosteroids [6] and 2 weeks treatment with oral prednisone [23] were evaluated on the inflammatory infiltrate in bronchial biopsies in patients with mild asthma. Using the data presented in those studies one can estimate the between-biopsy repeatability from repeated bronchoscopies in the placebo groups. From the figures in those reports it appeared that there was marked between-biopsy variability relative to the total variability for EG1, EG2 and AA1 positive cells, resulting in estimated ICC values in similar ranges to the present study: i.e. up to 0.84 for EG2+ cells in the study of BENTLEY et al. [23]. Relatively lower values can be obtained from the study of TRIGG et al. [6]. This may be due to the longer time interval between repeated bronchoscopies, pointing to the increase in variability with the duration of the interval. Furthermore, the standard deviation of differences between two biopsies (expressed as doubling cell numbers) that can be obtained from the data presented in those studies revealed similar values as in the present study. This suggests that the sample-size estimations that we reported for EG1, EG2 and AA1 positive cells are in keeping with those studies. Furthermore, our results extend those observations to power-calculations with respect to other inflammatory cell types.

Very recently, a study by RICHMOND et al. [8], aimed at the quantification of variability, showed that there is indeed considerable within-subject variation of inflammatory cell counts between biopsy sites and with time in patients with asthma. Reanalysing their between-site data revealed ICC values of 0.80 when considering all cell types together, and $0.25-0.80$ for the individual cell types, thereby demonstrating similar repeatability as in the present study. However, the variability between different bronchoscopies was somewhat greater.
In the present study, we expressed the repeatability either as coefficient of variation or as ICC. Appropriate assessment of repeatability assumes both coefficients to be independent of different mean values $[15,24]$. Since a coefficient of variation is calculated by dividing the standard deviation by its mean value for each individual separately, this assumption is fulfilled when the variability is proportional to the mean value. Indeed, we found that the difference between two counts was positively related to their mean for all of the inflammatory cell types. Furthermore, when looking carefully at the data of Richmond et al. [8], the variability also increased with increasing mean cell counts. This implies that there was heteroscedasticity, in other words, that the variability increased with increasing severity of the inflammatory cell infiltrate, which is to be avoided for statistical analysis [9]. In a recent paper, we reported a relationship between the cellular infiltrate in bronchial biopsies and the severity of bronchial hyperresponsiveness (BHR) [10]. This suggests that the variability of cell counts was increasing among subjects with mild, moderate and severe bronchial asthma as defined by BHR. A $\log$ transformation fulfills the assumption of homoscedasticity of cell counts and, therefore, allows valid calculation of ICC and statistical testing. Furthermore, a sample-size estimation based on such transformation seems to be appropriate in subjects with various degrees of asthma severity.

A $\log$ transformation is the only transformation that allows for a meaningful back-transformation of the mean and standard deviation $[15,25,26]$. Hence, we expressed the standard deviations of the differences between the two log-transformed counts in doubling cell numbers. The sample-size calculations were based on one doubling or halving of cell numbers, because a change from 20 to 10 cells $\cdot 0.1 \mathrm{~mm}^{-2}$ is likely to be of similar clinical relevance as a change from 10 to 5 cells $0.1 \mathrm{~mm}^{-2}$, as opposed to a change from 10 to 0 cells $\cdot 0.1 \mathrm{~mm}^{-2}$. Therefore, the analysis was performed on log-transformed cell counts for statistical as well as clinical reasons. We believe this leads to more appropriate and statistically more efficient sample size estimations with respect to intervention studies.

It has been suggested that the value of the intra-class correlation coefficient for a certain parameter should be at least 0.6 to be a useful measurement [17]. This was not fulfilled for each of the variables in the analysis of intra-observer, within-section and between-biopsy repeatability. This might be due to the selection of a study group that was very homogeneous with respect to those variables, which implicitly leads to relatively low betweensubject variation $[17,24]$. Therefore, it should be recognized that an intra-class correlation coefficient has no absolute meaning [27]. On the other hand, these results may indicate that for those cell types showing relatively low intra-class correlation coefficients, there is considerable variability between two areas within one biopsy section, and/or between two biopsy specimens. This illustrates that even within the lamina propria the infiltration of inflammatory cells might indeed be a patchy focal phenomenon, sometimes in clusters of indefinable numbers [6]. It can be argued that this stresses the importance of counting the largest possible area within a biopsy and/or averaging data obtained from multiple 
sections and/or biopsies. Alternatively, this clustering might provide specific information about the inflammatory process, sometimes requiring a semi-quantitative scoring method [7]. Such scoring methods seem to provide satisfactory reproducibility and good agreement with computerized video interactive quantification of inflammatory cells in bronchial biopsies [28]. Obviously, further research is needed to optimize the quantification of the cellular infiltrate, because bronchial biopsy specimens will remain the gold standard for assessing airway inflammation in asthma [29].

\section{References}

1. Djukanović R, Roche WR, Wilson JW, et al. State of the art. Mucosal inflammation in asthma. Am Rev Respir Dis 1990; 142: 434-457.

2. Holgate ST, Roche W, Djukanović R, Wilson J, Britten $\mathrm{K}$, Howarth P. The need for a pathological classification of asthma. Eur Respir J 1991; 4: 113s-122s.

3. McFadden ER. Asthma: morphologic-physiologic interactions. Am J Respir Crit Care Med 1994; 150: S23S26.

4. Laitinen LA, Laitinen A. Modulation of bronchial inflammation: corticosteroids and other therapeutic agents. $\mathrm{Am}$ J Respir Crit Care Med 1994; 150: S87-S90.

5. Jeffery PK, Wardlaw AJ, Nelson FC, Collins JV, Kay AB. Bronchial biopsies in asthma. An ultrastructural, quantitative study and correlation with hyperreactivity. Am Rev Respir Dis 1989; 140: 1745-1753.

6. Trigg CJ, Manolitsas ND, Wang JH, et al. Placebo-controlled immunopathologic study of four months of inhaled corticosteroids in asthma. Am J Respir Crit Care Med 1994; 150: 17-22.

7. Haahtela T, Laitinen A, Laitinen LA. Using biopsies in the monitoring of inflammation in asthmatic patients. Allergy 1993; 48: 65-69.

8. Richmond I, Booth H, Ward C, Walters EH. Intrasubject variability in airway inflammation in biopsies in mild to moderate stable asthma. Am J Respir Crit Care Med 1996; 153: 899-903.

9. Armitage P. Statistical Methods in Medical Research. 2nd Ed. Oxford, Blackwell Scientific Publications, pp. 1987; 179-183.

10. Sont JK, van Krieken JHJM, Evertse CE, Hooijer R, Willems LNA, Sterk PJ. The relationship between the inflammatory infiltrate in bronchial biopsies and clinical severity of asthma in patients treated with inhaled steroids. Thorax 1996; 51: 496-502.

11. Quanjer PhH, Tammeling GJ, Cotes JE, Pedersen OF, Peslin R, Yernault JC. Lung volumes and forced ventilatory flows. Eur Respir J 1993; 6 (Suppl. 16): 5-40.

12. Sterk PJ, Fabbri LM, Quanjer $\mathrm{PhH}$, et al. Airway responsiveness. Standardized challenge testing with pharmacological, physical and sensitizing stimuli in adults. Eur Respir J 1993; 6 (Suppl. 16): 53-83.

13. Djukanović R, Wilson JW, Lai CKW, Holgate ST,
Howarth PH. The safety aspects of fibreoptic bronchoscopy, bronchoalveolar lavage, and endobronchial biopsy in asthma. Am Rev Respir Dis 1991; 143: 772-777.

14. Workshop summary and guidelines. Investigative use of bronchoscopy, lavage and bronchial biopsies in asthma and other airways diseases. Eur Respir J 1992; 5: 115-121.

15. Chinn S. Statistics in respiratory medicine 3. Scale, parametric methods, and transformation. Thorax 1991; 46: $536-538$.

16. Bland JM, Altman DG. Statistics Notes. Measurement error and correlation coefficients. BMJ 1996; 313: 41-42.

17. Chinn S. Statistics in medicine 2. Repeatability and method comparison. Thorax 1991; 46: 454-456.

18. Fraenkel DJ, Bardin PG, Sanderson G, Lampe F, Johnston SL, Holgate ST. Lower airways inflammation during rhinovirus colds in normal and asthmatic subjects. Am J Respir Crit Care Med 1995; 151: 879-886.

19. Bradley BL, Azzawi M, Jacobson M, et al. Eosinophils, T-lymphocytes, mast cell, neutrophils, and macrophages in bronchial biopsy specimens from atopic subjects with asthma: comparison with biopsy specimens from atopic subjects without asthma and normal control subjects and relationship to bronchial hyperresponsiveness. J Allergy Clin Immunol 1991; 88: 661-674.

20. Bentley AM, Menz G, Storz Chr, et al. Identification of T-lymphocytes, macrophages, and activated eosinophils in the bronchial mucosa in intrinsic asthma. Relationship to symptoms and bronchial responsiveness. Am Rev Respir Dis 1992; 146: 500-506.

21. Azzawi M, Bradley B, Jeffery PK, et al. Identification of activated T-lymphocytes and eosinophils in bronchial biopsies in stable atopic asthma. Am Rev Respir Dis 1990; 142: 1407-1413.

22. Sullivan P, Bekir S, Jaffar Z, Page C, Jeffery P, Costello J. Anti-inflammatory effects of low-dose oral theophylline in atopic asthma. Lancet 1994; 343: 1006-1008.

23. Bentley AM, Hamid Q, Robinson DS, et al. Prednisolone treatment in asthma. Reduction in the numbers of eosinophils, T cells, tryptase-only positive mast cells, and modulation of IL-4, IL-5, and interferon-gamma cytokine gene expression within the bronchial mucosa. Am J Crit Care Med 1996; 153: 551-556.

24. Chinn S. The assessment of methods of measurement. Stat Med 1990; 9: 351-362.

25. Altman DG. Practical Statistics for Medical Research. London, Chapman and Hall, 1991.

26. Peat JK, Unger WR, Combe D. Measuring changes in logarithmic data, with special reference to bronchial hyperresponsiveness. J Clin Epidemiol 1994; 47: 1099-1108.

27. Müller R, Büttner P. A critical discussion of intraclass correlation coefficients. Stat Med 1994; 13: 2465-2476.

28. Sont JK, Willems LNA, van Krieken JHJM, Sterk PJ. Bronchial biopsies in atopic asthma: intra-observer variability of inflammatory cell counts per $\mathrm{mm}^{2}$ and agreement with semi-quantitative scores. Eur Respir J 1994; 7: 433s.

29. Jeffery PK. Bronchial biopsies and airway inflammation. Eur Respir J 1996; 9: 1583-1587. 